\title{
MEASURING THE MORPHOLOGY AND DYNAMICS OF THE SNAKE RIVER BY REMOTE SENSING
}

\author{
CARL J. LEGLEITER $\uparrow$ BRANDON T. OVERSTREET \\ UNIVERSITY OF WYOMING $\downarrow$ LARAMIE
}

\begin{abstract}
$\uparrow$ AbStraCt
The Snake River is an essential feature of Grand Teton National Park, and this dynamic fluvial system maintains diverse habitats while actively shaping the landscape. The complex, ever-changing nature of the river make effective characterization difficult, however; traditional field methods are illsuited for this task. Remote sensing provides an appealing alternative that could facilitate resource management while providing novel insight on the controls of channel form and behavior. This study continued our ongoing assessment of the potential to measure the morphology and dynamics of large, complex rivers such as the Snake via remote sensing (Figure 1). More specifically, we acquired hyperspectral images and bathymetric LiDAR data in August 2012 and are now comparing the depth retrieval capabilities of these sensors; in situ observations of water column optical properties inform this analysis as well. In addition to bathymetry, we are investigating the feasibility of using these data to infer bottom reflectance and hence delineate various substrates, such as gravel and submerged aquatic vegetation. Another new aspect of our research focuses on estimating flow velocities from the hyperspectral images and high-resolution digital aerial photography acquired simultaneously. Extensive field measurements of velocity will help us develop this approach. Similarly, measurements of sediment grain size on exposed bar surfaces will be used to assess whether particle size can be inferred from the highresolution photography. Remotely sensed data also are being used to identify areas of erosion and deposition and hence quantify the sediment flux associated with changes in channel morphology. Additional
\end{abstract}

hyperspectral and bathymetric LiDAR data will be acquired in 2013, along with field measurements of depth, velocity, and bottom type.

\section{$\uparrow$ INTRODUCTION}

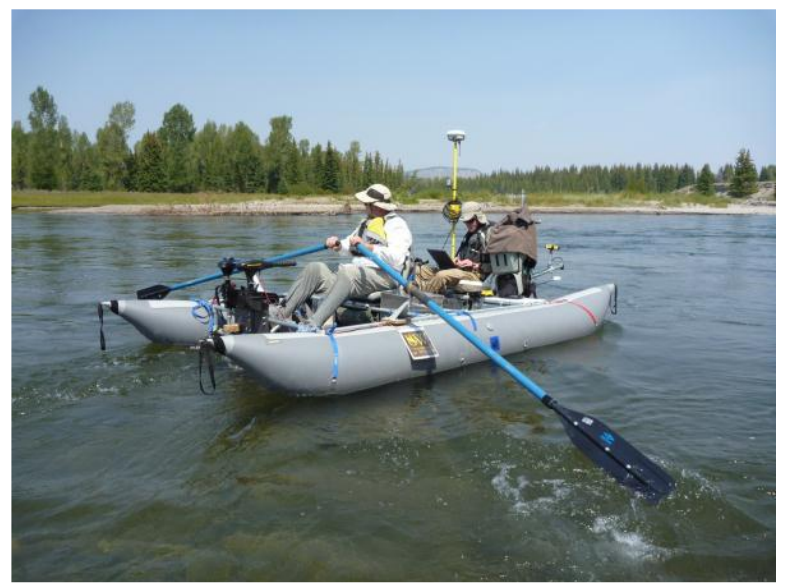

Figure 1. Cataraft used for measuring field spectra along the Snake River. Photo by Brandon Overstreet.

A defining feature of the Teton landscape, the Snake River plays an important role in the geomorphology and ecology of Jackson Hole and provides visitors to Grand Teton National Park with abundant recreational opportunities. This dynamic fluvial system collects water and sediment from a large, mountainous drainage basin and conveys these materials across the valley floor via various mechanisms of flow and sediment transport. These processes interact to produce coherent patterns of sediment transfer and storage that are manifested as distinctive landforms - channels, bars, floodplains, and 
terraces. These geomorphic surfaces are colonized by vegetation but eventually reclaimed as the river shifts laterally, incises new channels, or reoccupies former flow paths. This perpetual reworking of the riparian zone creates a patchy mosaic of habitat conditions that supports a diversity of terrestrial and aquatic organisms, including such iconic species as bald eagles, beaver, native trout, and moose. The potential to view such wildlife, along with the unique scenery in part created by the Snake, makes this fluvial environment a source of considerable enjoyment by the public, for whom the river and surrounding National Park have been protected and preserved.

Managing these natural resources is the responsibility of the National Park Service, but this important task is complicated by the same variability and dynamism that make the Snake River such a vibrant element of the landscape. Basic information on the river's form and behavior are needed for resource assessment and monitoring purposes, but the logistical constraints associated with conventional field methods make even sparse data difficult to obtain. Measuring channel and floodplain topography, flow conditions, and streambed characteristics over long reaches is simply not practical in such a heterogeneous riverine environment. Moreover, the channel changes that occur during each spring's snowmelt imply that maintaining an accurate, current database would require annual surveys. Information of this kind would facilitate various ongoing ecological and geomorphic investigations while enabling the Park Service to more readily achieve certain management objectives. For example, studies of native cutthroat trout would benefit from a more detailed knowledge of the physical habitat conditions (e.g., depth, velocity, and bed material grain size) preferred by these species during different life stages. Similarly, research on the effects of flow regulation on floodplain inundation, bed mobility, and general channel stability, along with related efforts to develop reach-scale sediment budgets, would benefit from more extensive, higher resolution topographic data. For resource management, current information on channel depths, the distribution of bars, and the location of obstructions (e.g., accumulations of large woody debris) would allow navigability by rafts to be assessed more easily and could help recreational boaters to avoid potentially hazardous situations. For many reasons, then, an enhanced capacity to characterize the morphology and dynamics of the Snake River would be of great value.

Remote sensing techniques could provide such a capacity by enabling more efficient measurement of several key river attributes. A quantitative, remote sensing-based approach would have several distinct advantages in this context: 1) a synoptic perspective that allows long segments of broad riparian zones to be mapped in a matter of hours rather than weeks, 2) continuous, high-resolution data that capture the spatial variability of the riverine environment far more effectively than traditional methods based on isolated cross-sections, and 3) more frequent coverage that could not only facilitate monitoring but also lead to an improved understanding of the fluvial processes that drive channel change and thus create, modify, and maintain diverse terrestrial and aquatic habitats.

Research on the application of remote sensing to rivers has progressed rapidly over the past decade (Marcus and Fonstad, 2010). For example, our earlier work demonstrated the feasibility of mapping flow depth from optical data (Legleiter et al., 2004, 2009). Field measurements and digital aerial photography collected along the Snake River in August 2010 also indicated that reasonably accurate depth estimates could be derived from relatively basic images of this kind (Legleiter, in press). A subsequent study demonstrated that river bathymetry could even be mapped from space, with high-resolution multispectral images from the WorldView2 sensor (Legleiter and Overstreet, 2012). Our results thus suggest that integrated, spatially explicit analysis of remotely sensed data could enable scientists and managers to more efficiently characterize complex river systems like the Snake.

\section{Research hypothesis and specific aims}

The primary goal of our research in Grand Teton National Park is to apply remote sensing methods to an important problem that is not only of scientific interest but also of direct relevance to current management needs: characterizing the morphology and dynamics of the Snake River. This effort will yield insight on factors influencing channel form and behavior and facilitate the Park Service's efforts to protect this resource. We have a more general research interest in the remote sensing of rivers, but the Snake River is one of our primary field sites for developing and testing new methods. This dynamic fluvial system provides an opportunity to critically evaluate the feasibility of mapping a large, braided river from various types of image data. This project is also consistent with our overarching research objective: to understand the mechanisms by which flow, sediment transport, and channel form interact to direct a river's morphologic evolution. Motivated by these goals, our efforts over the past year have focused on the following specific aims: 
1) Obtain field measurements of reflectance, water column optical properties, water depth, flow velocity, and substrate composition to assess the feasibility of retrieving key geomorphic parameters such as bathymetry, velocity, and particle size from optical image data.

2) Extend our image time series through 2012 by acquiring hyperspectral data, high-resolution digital aerial photography, and both near-infrared topographic LiDAR and water-penetrating bathymetric green LiDAR.

3) Quantify the sediment flux associated with channel change by measuring volumes of erosion and deposition volumes from repeat LiDAR coverage acquired in 2007 and 2012.

\section{$\downarrow$ STUDY AREA}

This effort to characterize channel form and behavior via remote sensing focuses on the Snake River in Grand Teton National Park. This dynamic fluvial system is well-suited for such an investigation because the river encompasses a range of channel morphologies, valley floor environments, and disturbance regimes that not only pose a challenging test of remote sensing methods but also will allow us to examine various factors controlling rivermorphology. For example, the Snake includes both meandering and braided segments that are influenced by variations in slope and sediment supply, differences in streambank composition and riparian vegetation, a post-glacial legacy, and a strong tectonic signal. Field measurements and image data from the Snake thus allow us to draw comparisons among a variety of stream reaches in terms of both their amenability to remote mapping and their geomorphic controls. In addition, the Snake is an attractive site for study because the river features: 1) clear water conditions conducive to remote sensing of flow depths, 2) a pair of stream gages that provide a continuous record of river discharge, 3 ) relatively little direct human impact, apart from flow regulation by Jackson Lake Dam, and 4) a well-documented history of channel change based on archival aerial photography (Nelson et al., In press). In any given year, a sizable portion of the Snake River could experience significant morphologic adjustment as a result of high snowmelt runoff; both existing and planned remotely sensed data sets provide an effective means of characterizing these dynamics.

Our 2012 field campaign involved extensive data collection along the Snake River and encompassed a broad range of channel configurations (Figure 2). We covered the segment from Pacific Creek downstream to Moose, with much of our effort focused effort on a pair of meander bends: 1) Swallow Bend, located at $537500 \mathrm{~m} \mathrm{E}, 4851200 \mathrm{~m} \mathrm{~N}$; and 2) Rusty Bend, located at $535160 \mathrm{~m} \mathrm{E}, 4849650 \mathrm{~m} \mathrm{~N}$ (UTM Zone $12 \mathrm{~N}$ ). In addition to these two detailed study sites, we performed a longitudinal survey using a specially designed cataraft outfitted with equipment for measuring flow depths, velocities, and various optical properties, including digital photographs of the substrate. (Figure 1)

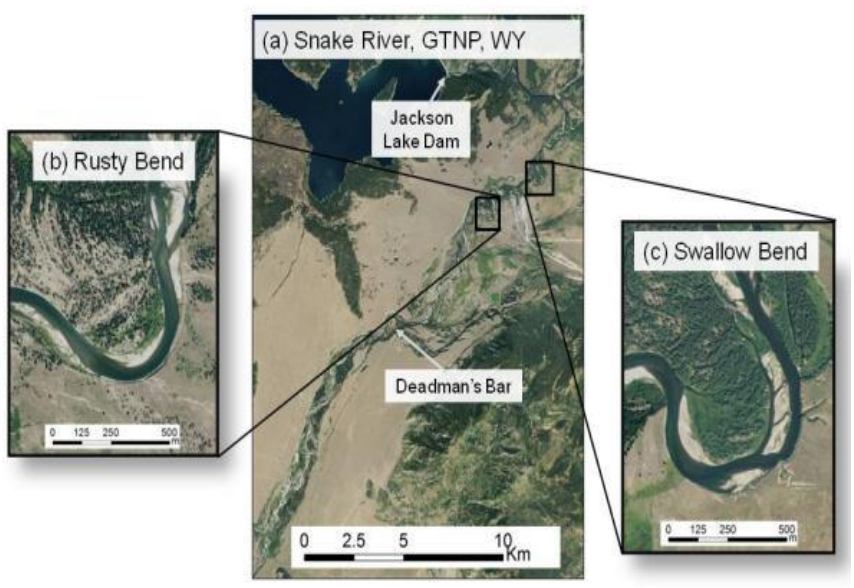

Figure 2. WorldView2 satellite image of the Snake River acquired 13 September 2011 showing the locations of our two primary study reaches: Rusty and Swallow Bends.

\section{$\uparrow$ METHODS}

For 2012, the general strategy of our investigation was to 1) make field measurements of flow conditions, bed material composition, and optical properties along the Snake River, 2) obtain various types of remotely sensed data from the riparian corridor, 3) develop and evaluate image processing methods for retrieving key geomorphic and habitat parameters from these image data sets, and 4) combine newly acquired and archival LiDAR coverage to examine channel changes occurring between 2007 and 2012. The data acquired in 2012 also provide a basis for planning future remote sensing missions, with additional flights scheduled for August 2013. This project thus involved a combination of geospatial data analysis and field work; these two components are described below.

\section{Remotely sensed data and image processing}

Our previous research on the Snake River has demonstrated the feasibility of mapping water depth from publicly available aerial photography (Legleiter, 
in press) and satellite images (Legleiter and Overstreet, 2012), but in 2012 we focused on two new types of remotely sensed data. In collaboration with the National Center for Airborne Laser Mapping (NCALM), we acquired airborne hyperspectral images, high resolution digital aerial photography, and both near-infrared LiDAR for measuring sub-aerial topography and green LiDAR for measuring channel bathymetry. These data sets are illustrated in Figures 3 and 4.
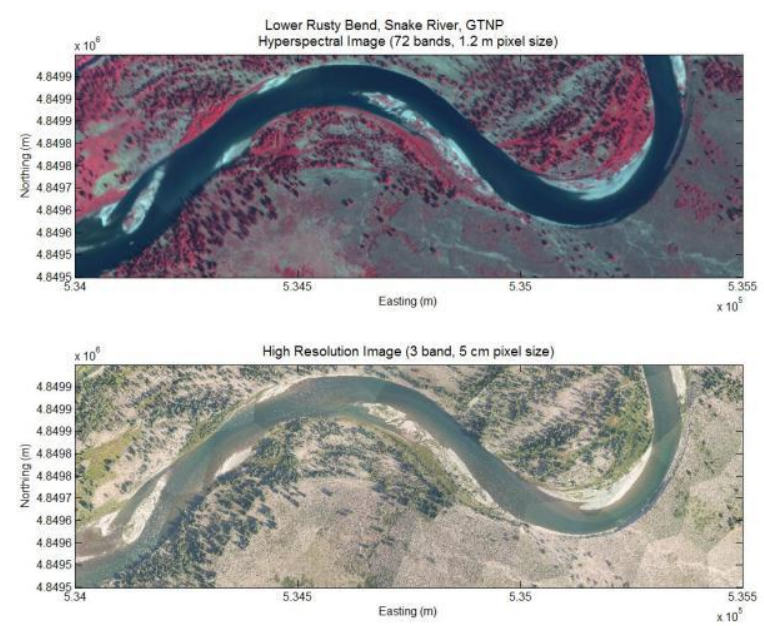

Figure 3. Hyperspectral image data and high-resolution aerial photography acquired from our Rusty Bend study site in August 2013, though a collaboration with the National Center for Airborne Laser Mapping (NCALM).

The hyperspectral images were acquired with a CASI 1500 sensor deployed at several different altitudes and aircraft velocities to yield data with pixel sizes ranging from 0.6 to $1.2 \mathrm{~m}$, with up to 72 spectral bands. These data were only recently delivered by NCALM, with a single $1.2 \mathrm{~m}$-resolution image having been processed to date, so our analysis of these images remains in a very early stage. Although the images we received were radiometrically calibrated and georeferenced by NCALM, alignment with our field measurements was unacceptable and we are now reprocessing the raw data acquired during the flight to achieve closer co-registration with our field data. The high-resolution aerial photography shown above was obtained with a DIMAC LiGHT+ medium format digital aerial camera system that provided $5 \mathrm{~cm}$ pixel sizes with a standard, three-band, true color spectral configuration. These data were geo-referenced and assembled into a mosaic by NCALM, and alignment with our field-based data sets is much better than for the hyperspectral images. The primary issue with the aerial photography is the seams evident where the individual frames were combined into a mosaic.

NCALM specializes in LiDAR data collection, processing, and analysis, and acquired two types of LiDAR data for our project. Their standard Optech Gemini system operates at a NIR wavelength $(1064 \mathrm{~nm})$ and features a high scan frequency that yields a dense coverage of elevation measurements from exposed surfaces. For the channel proper, however, the NIR laser pulses are strongly absorbed by water and do not reach the bottom. A second, green $(532 \mathrm{~nm}) \mathrm{LiDAR}$, the Optech Aquarius, is specifically intended for measuring bathymetry in addition to topography, although the system had been deployed only in coastal settings prior to this study of the Snake River. The two LiDAR data sets are shown in Figure 4 , with the additional in-stream detail provided by Aquarius clearly evident. Deliverables from NCALM included both gridded, $1 \mathrm{~m}$ resolution digital elevation models and the original, raw point clouds in a LAS file format. Because these data sets were provided only recently, our analysis of the LiDAR is an early stage as well. Nevertheless, the remotely sensed data acquired in 2012 extend our time series from 2009 through the present and thus help to advance our ongoing investigation of channel change.

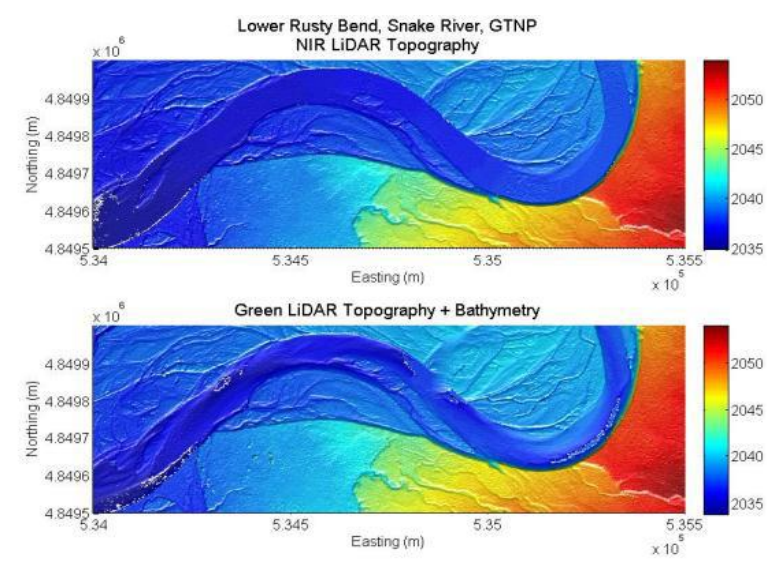

Figure 4. LiDAR data acquired by NCALM from the Snake River in August 2013.

\section{Field data collection}

In addition to the remote sensing component described above, our study also involved extensive field work intended to validate image-derived river information and support our geomorphic research. As part of our overall effort to advance the remote sensing of rivers, the development of which has been hindered by a lack of in situ observations, we made direct field measurements of several optical characteristics of the Snake River. Reflectance spectra were recorded above the water surface using an Analytical Spectral Devices (ASD) FieldSpec3 spectroradiometer. A 100\% reflectant Spectralon calibration panel was used to establish a white reference prior to each round of 
measurements. The spectroradiometer was mounted on a specially designed cataraft and configured to record spectra once each second as we traversed the river on a series of channel-spanning transects and longitudinal profiles (Figure 1). Flow depths were recorded simultaneously using the survey instrumentation described below. This protocol thus provided paired observations of depth and reflectance needed to develop and refine bathymetric mapping algorithms. Moreover, these data extended the range of river conditions under which spectra have been measured from shallow, wadable streams (Legleiter et al., 2009) to a deeper, larger channel with more diverse bottom types. For example, our Swallow and Rusty Bend study sites were up to $3 \mathrm{~m}$ deep and featured submerged aquatic vegetation and bright-colored clay bedrock substrates, respectively. In previous field seasons we collected spectra only along cross-sections located in our two primary study sites, but the addition of downstream profiles in 2012 further extended the range of river conditions we have observed and provided a greater sample size as well.

In addition to bathymetry, the composition of the streambed also might be mapped via remote sensing. To further explore this possibility and build upon the spectral library of different substrate types we measured directly with the ASD in 2011, we collected a series of substrate images. A GoPro camera with a waterproof housing was mounted beneath our raft during spectral data collection and configured to automatically acquire an image every second. By combining the time stamps for these images with those of the spectra and GPS positions, we obtained paired, geo-referenced observations of depth, reflectance, and substrate composition. An example substrate image from Swallow Bend is shown in Figure 5.

The optical properties of the water column impose an important constraint on remote mapping of bathymetry and/or bottom type, and we collected field data on several characteristics of Snake River water. We developed and implement several innovative field methods for collecting such data during our 2012 campaign, and the increased efficiency allowed us to acquire a larger data set spanning a broader range of conditions. For example, we designed a measurement crane for positioning a waterproof, upward-facing detector connected to the spectroradiometer at various depths within the water column at which we recorded the amount of downwelling radiant energy propagating to each depth (Figure 6). These data were used to calculate a diffuse attenuation coefficient at each wavelength following the procedure outlined by Mishra et al. (2005). In addition, we used a new WetLabs ac-s to directly measure two key inherent optical properties of the water column, the absorption and attenuation coefficients, $a$ and $c$. A second WetLabs instrument, called the EcoTriplet, also provided observations of the scattering coefficient $b$, turbidity, and concentrations of chlorophyll and colored dissolved organic matter (CDOM). A Eureka Environmental Manta 2 multi-probe was used to measure blue-green algae concentrations as well. These optical data were collected on several dates at discrete sites along the Snake River (for the irradiance profiles and ac-s measurements) and along the path of the raft, for the EcoTriplet and Manta 2 sensors. Ancillary data in support of these measurements included water samples analyzed for suspended sediment concentration.

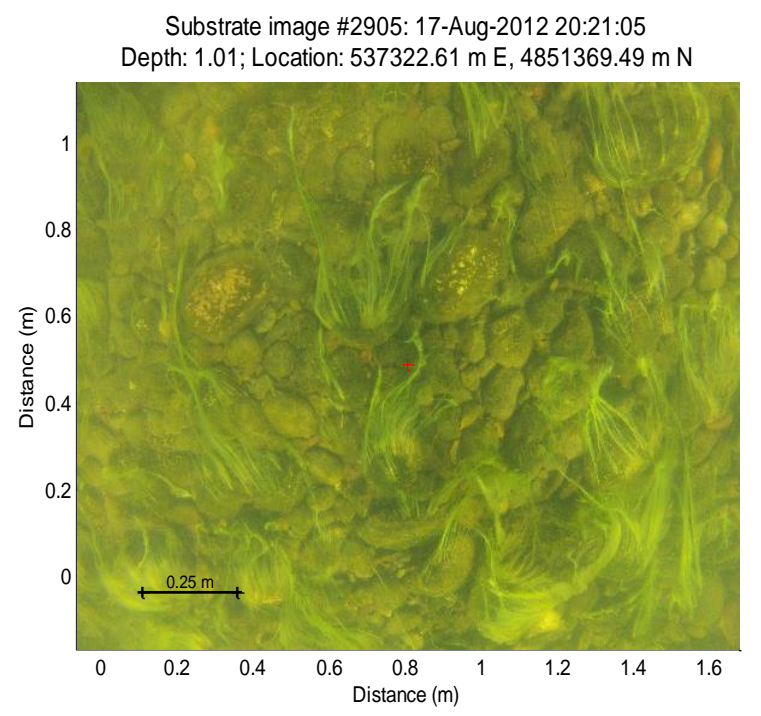

Figure 5. GoPro substrate image from Swallow Bend showing submerged aquatic vegetation present on the bed.

A second key component of our field effort was a survey of channel bed topography. These data were collected using a high-precision (sub-centimeter) real-time kinematic GPS receiver that was attached to a survey rod for measuring terrestrial surface elevations. Survey points were arranged along crosssections traversing exposed bars and shallow areas of the active channel and selected so as to emphasize important breaks in slope, such as the top and base of stream banks. For areas that were too deep to wade safely, the GPS receiver was mounted on the cataraft and configured to record water surface elevations while communicating with an echo sounder that measures flow depths; subtracting the depth from the water surface elevation yielded measurements of the bed elevation. Over $22 \mathrm{~km}$ of the Snake River was surveyed in this manner. Measurements were obtained along a series of 6 transects in our detailed study sites as well as longitudinal profiles recorded as we 
progressed downstream each day. These field measurements allowed us to establish relationships between depth and reflectance, both from field spectra and, eventually, hyperspectral images.

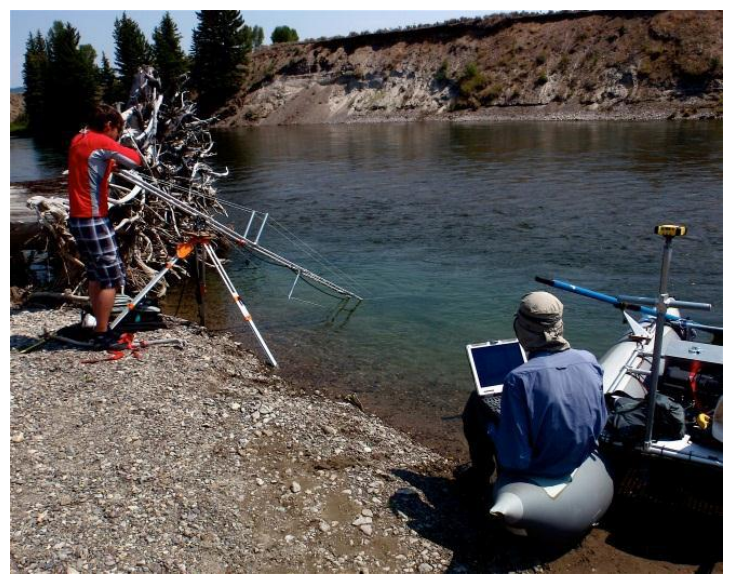

Figure 6. Measurement crane used to facilitate measurements of the downwelling radiant energy at different depths within the water column.

In an effort to expand the range of river attributes that can be derived from remotely sensed data to include information on flow velocity, we measured flow conditions within the Snake River using an acoustic Doppler current profiler (ADCP). This instrument was deployed from a kayak outfitted with a specialized mounting system (Figure 7) and recorded flow velocities in a series of cells distributed vertically throughout the water column. The ADCP measured streamwise, cross-stream, and vertical velocity components at a frequency of once per second and thus provided a very detailed characterization of the flow field. We also used the ADCP to measure river discharge by integrating the product of depth and velocity as we moved across the channel. In addition to cross-sections located in our two primary study sites at Swallow and Rusty Bends, we recorded velocities along profiles oriented down the river. The ADCP also recorded flow depths and thus provided an additional source of field data for evaluating remotely sensed bathymetry.

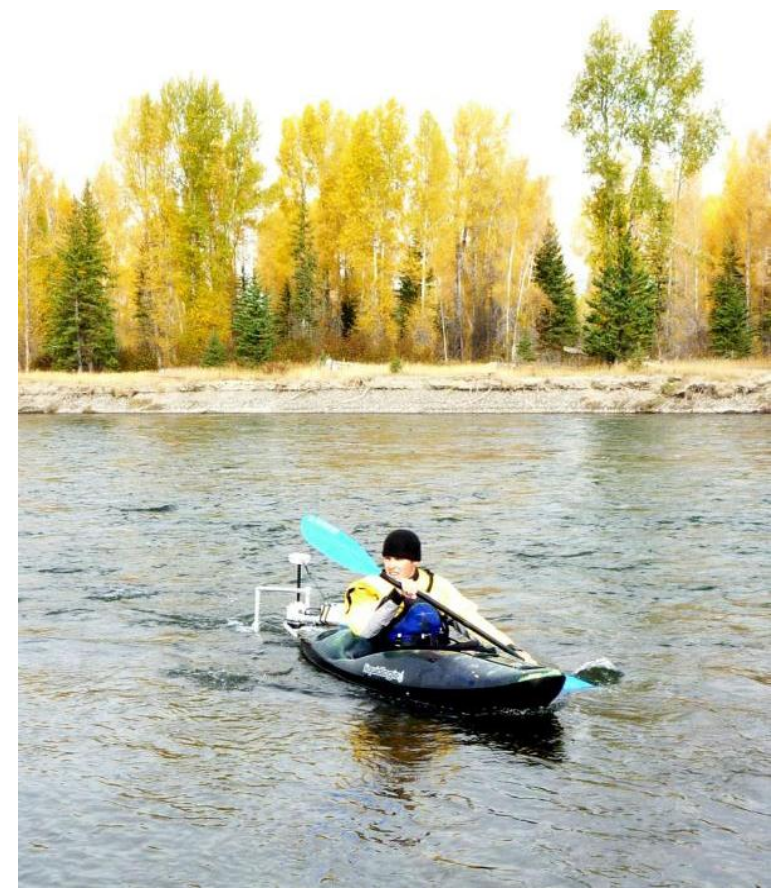

Figure 7. Flow velocities were measured with an acoustic Doppler current profiler (ADCP) deployed from a kayak, shown here during a September deployment intended to characterize the flow field at a lower discharge.

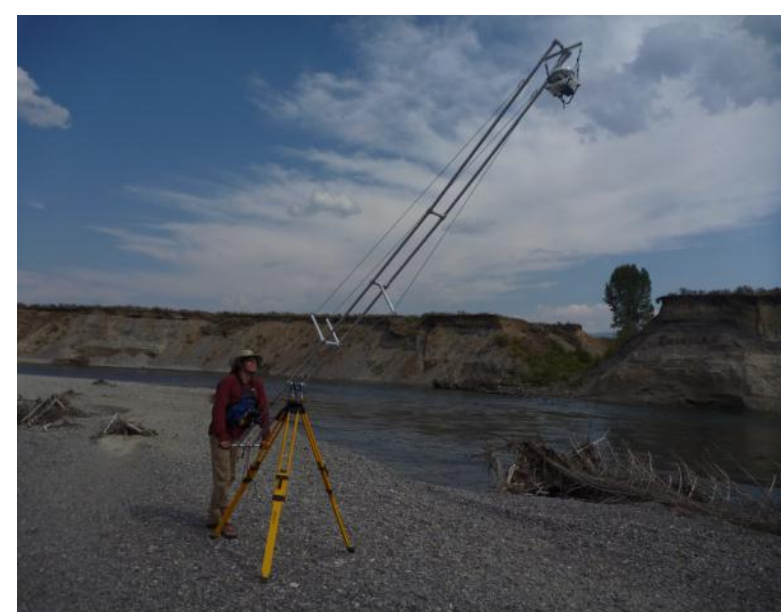

Figure 8. Measurement crane used to acquire digital photographs of bar surfaces that will be used to estimate sediment grain size. We also intend to explore the possibility of mapping grain size from the high-resolution digital aerial photography shown in Figure 3.

In addition, data acquired with the ADCP will support future work on the interactions between flow processes, bed material transport, and the evolution of channel form. To pursue this more general geomorphic research objective, we made a second round of flow measurements in late September at a lower discharge than during our primary field 
campaign in August. The latter data set will allow us to more closely examine the influence of bar-pool topography on flow patterns through meander bends at a range of flow stages (Legleiter et al., 2011). To further expand this range, we have just (June 2013) completed a third set of measurements at a higher discharge more likely to mobilize bed material and lead to scour and fill.

The geomorphic processes responsible for channel change are highly sensitive to sediment grain size, but this type of information was not readily available for the Snake River. To facilitate our analysis of the river's sediment budget, we used the measurement crane shown in Figure 8 to elevate a camera and obtain photographs of bar surfaces. Grain size information will be derived from these images using established procedures (Warrick et al., 2009). To scale up this type of grain size mapping, we will also evaluate the possibility of inferring particle size from image texture metrics derived from the highresolution digital aerial photography.

\section{$\downarrow$ RESULTS}

Our previous work has focused on spectrallybased depth retrieval from remotely sensed data and field-based characterization of the optical properties of the water column. Although this work is ongoing, these topics have been addressed in annual reports from 2010 and 2011. For this summary of our 2012 activities, we shift our focus to several new, but related aspects of our research, keeping in mind our overall research objective of developing an advanced, operational capacity for deriving various kinds of river information from remotely sensed data. Here, we describe some preliminary results from our current efforts to: 1) map river bathymetry from NIR and green LiDAR, 2) identify different bottom types on the basis of their unique spectral characteristics, 3) infer flow velocities from hyperspectral images, and 4) quantify volumes of erosion and deposition associated with bank failure and channel change.

\section{Measuring river bathymetry with green LiDAR}

Whereas our earlier work has emphasized mapping bathymetry from passive optical image data based on relationships between depth and reflectance, in 2012 we began exploring a new means of characterizing channel morphology. LiDAR has become the preferred method of measuring terrestrial surface elevations for Earth science applications, but the NIR laser pulses emitted by standard LiDAR systems are strongly absorbed by water, implying that these sensors cannot detect the channel bed. One solution to this problem, advocated in a previous study (Legleiter, 2012), is to combine depth estimates derived from optical images with LiDAR topography for exposed bars and floodplains to obtain a complete topographic representation of the riparian landscape. Recently developed green LiDAR systems, however, might provide a more efficient means of obtaining such data. Because the shorter-wavelength green laser does penetrate through water to some finite depth, submerged as well as sub-aerial topography can be measured with a single instrument.

Data acquired by NCALM's new Aquarius sensor in August 2012 along the Snake River allowed us to evaluate the potential for mapping channel morphology via this new technology. NIR topographic LiDAR were obtained as well, and we combined the two data sets to calculate water depths as the difference between the elevations recorded by the NIR LiDAR, which represent the water surface, from the elevations from the green LiDAR, which presumably were based on returns from channel bed. The resulting bathymetric map is shown in Figure 9A, which depicts our Rusty Bend field site. For the most part, depths inferred from the two LiDAR data sets are hydraulically reasonable, spatially coherent, and in good agreement with the field-based measurements shown in Figure 9B.

Also prominent in the bathymetric map, however, are a number of gaps, most notably in the deepest part of the bend at the upper end of the reach and in the center of the reach where the channel curves to the left. These gaps represent areas from which no green LiDAR returns were recorded and coincide with the deepest pools at this site. These depth retrieval errors are expressed as large positive residuals, defined as the field-measured depth minus the LiDARderived depth, in Figure 9C. The distribution of residuals in Figure 10 shows that although errors were minimal for much of the channel, a tendency to underestimate depth was indicated by numerous positive residuals; the mode at $2 \mathrm{~m}$ was associated with the data gaps in the pools.

These observations suggest that the LiDAR system as configured during this flight was not capable of resolving the full depth of pools on the basis of discrete return data. Because one of the purported advantages of green LiDAR is enhanced penetration depth relative to passive optical remote sensing, these results were unexpected and disappointing. Earlier research has shown that accurate depth estimates could be obtained for pools exceeding $2 \mathrm{~m}$ in depth from satellite images, implying that the hybrid optical/NIR 
LiDAR strategy might be more reliable than green LiDAR. Our colleagues from NCALM also were surprised by these results and are currently exploring a different processing strategy that takes advantage of the full waveform of the laser pulse rather than discrete returns. This approach could yield more reliable bathymetry across a broader range of depths, but further testing is required.
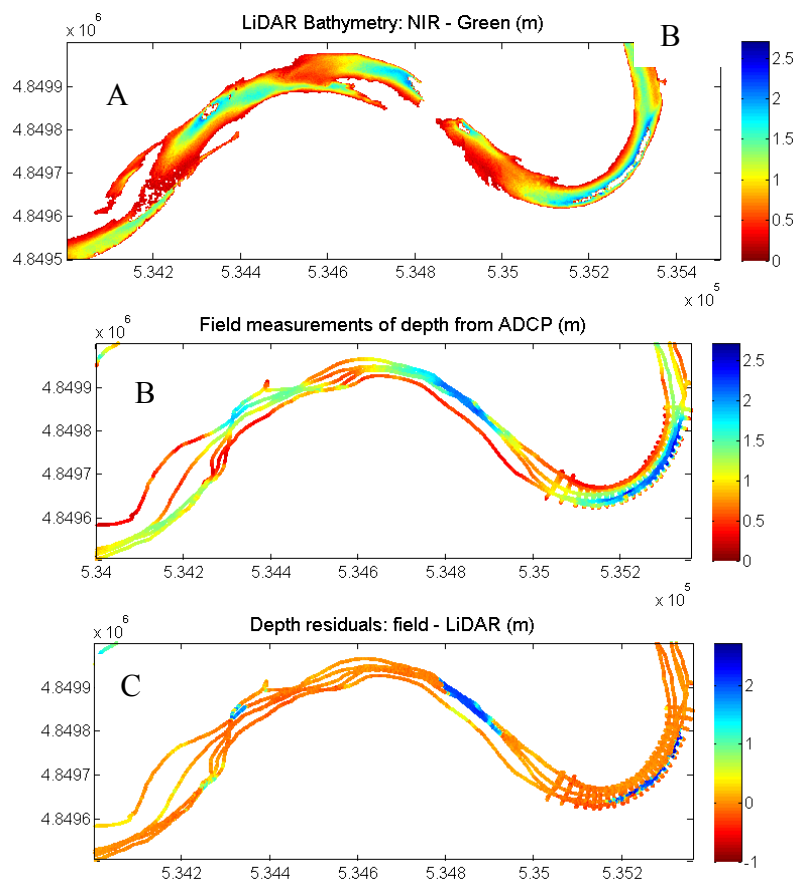

Figure 9. (A) Bathymetric map derived from NIR and green LiDAR from Rusty Bend; (B) field measurements of depth; and $(\mathrm{C})$ depth retrieval residuals. Flow from right to left.

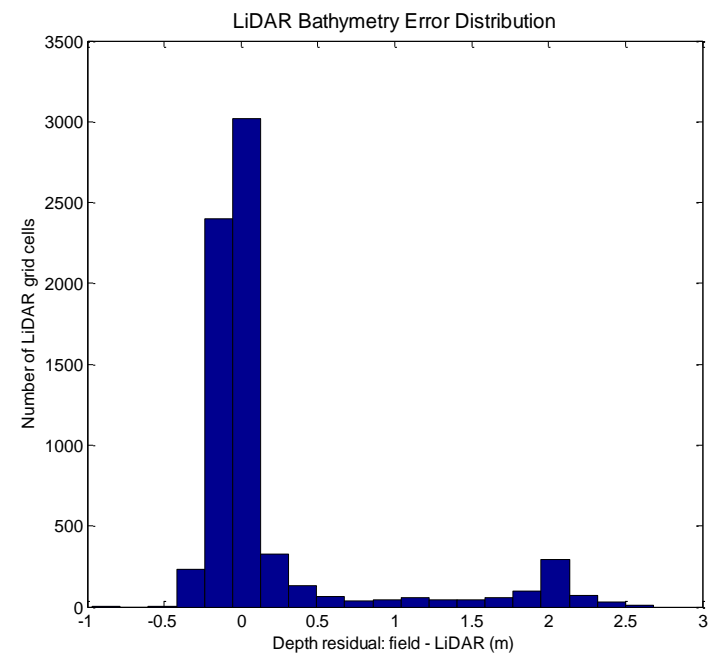

Figure 10. Distribution of depth retrieval residuals, defined as the difference between field-measured and image-derived depths, for Rusty Bend.

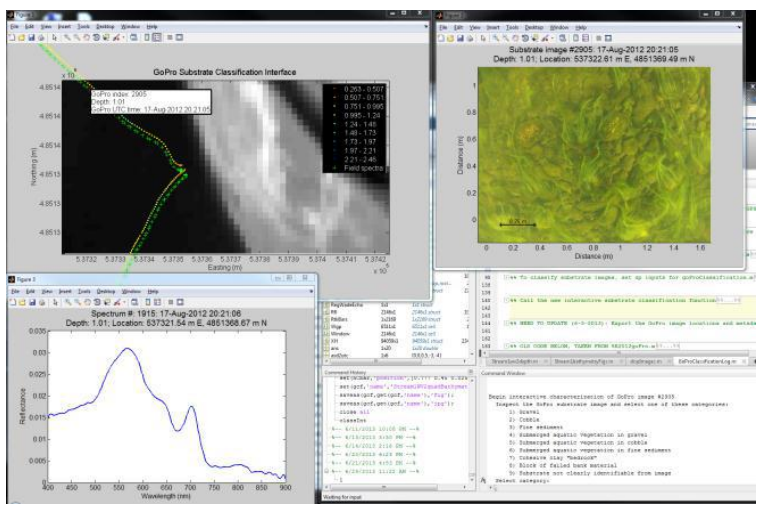

Figure 11. Graphical user interface for classifying substrate images of the Snake River and inspecting the spectral characteristics of different bottom types.

\section{Mapping the riverbed via optical remote sensing}

Another potential advantage of passive optical remote sensing is the availability of multiple spectral bands that might be used to infer other river attributes in addition to depth. For example, if the influence of the water column on the reflectance signal can be accounted for and removed, the bottom reflectance can be isolated and used to delineate various substrate types. Although this approach has been applied in coastal environments, we are not aware of any previous studies that have attempted to extend this approach to the fluvial environment. Our efforts to do so are in an early stage, but we have acquired a valuable field data set for pursuing this objective. By deploying the echo sounder, ASD spectroradiometer, and GoPro camera from our cataraft, we obtained paired observations of depth, reflectance, and bottom composition. Because each of these measurements were recorded once each second during multiple passes down the Snake River, we have thousands of spectra and substrate images to process. To facilitate this process, we have developed a user interface, shown in Figure 11, for selecting points from a map, querying the nearest substrate image and reflectance spectrum, and assigning the substrate at that location to one of several classes: gravel, cobble, or fine sediment with or without submerged aquatic vegetation, cohesive clay bedrock, and failed bank material. For the gravel and cobble classes, the user is also prompted to measure a representative particle size on the image, which canefforts to do so are in an early stage, but we have acquired a valuable field data set for pursuing this objective. By deploying the echo sounder, ASD spectroradiometer, and GoPro camera from our cataraft, we obtained paired observations of depth, reflectance, and bottom composition. Because each of these measurements were recorded once each second during multiple passes down the Snake River, 
we have thousands of spectra and substrate images to process. To facilitate this process, we have developed a user interface, shown in Figure 11, for selecting points from a map, querying the nearest substrate image and reflectance spectrum, and assigning the substrate at that location to one of several classes: gravel, cobble, or fine sediment with or without submerged aquatic vegetation, cohesive clay bedrock, and failed bank material. For the gravel and cobble classes, the user is also prompted to measure a representative particle size on the image, which can be converted to units of millimeters based on the known image scale. For images with submerged vegetation, an ordinal ranking of stem density is made as well. These data will thus form the basis for new algorithms for discriminating fine from coarse sediment, identifying vegetation, and potentially estimating algal biomass.

\section{Inferring flow velocity fron hpyerspectral images}

A second attribute that potentially could be inferred from high-resolution hyperspectral image data is flow velocity. The basis for this approach is the common field observation that areas of faster flow tend to have rougher, more irregular water surfaces, with white water in rapids being an extreme case. The texture of the water surface in turn exerts a primary control on the reflectance characteristics of the airwater interface. As the roughness of the water surface increases, surface reflectance also tends to increase because more of the individual facets of the irregular surface are oriented toward the sun and produce stronger specular reflections. If the surface component of the total reflectance signal can be identified and isolated, a correlation between surface reflectance and flow velocity could be established. Although this innovative method has not been tested for actual image data from real rivers, a recent study conducted in an outdoor flume showed a strong connection between the reflectance of the water surface and the texture (i.e., microtopography) of that surface, which was in turn related to flow velocities (Legleiter and Overstreet, In press).

We are now attempting to scale up this approach by isolating the water surface reflectance, or glint, from the hyperspectral image data acquired in 2012, shown in Figure 12A. The intensity of this glint signal is derived from the image spectra by measuring the depth of an absorption feature at a wavelength of $760 \mathrm{~nm}$ associated with oxygen gas in the atmosphere. For pixels with a greater contribution from the surface, such atmospheric effects are more prominent in the reflectance signal. In rivers, the texture of the water surface is influenced by the combination of flow depth $d$ and velocity $v$, two variables that are used to define a non-dimensional quantity known as the Froude number: $F r=v /(g d)_{1 / 2}$, where $g$ is the acceleration due to gravity. Portions of the channel with higher Froude numbers (i.e., higher velocities and/or shallower depths) such as riffles tend to have a rougher water surface texture and presumably a greater surface reflectance. To examine this relationship, we produced a surface glint intensity image based on the oxygen absorption band (Figure 12B) and computed the Froude number from our ADCP field measurements (Figure 12C). Comparison of these two maps indicates a consistent spatial pattern, with areas of greater glint intensity coinciding with higher Froude numbers. These initial results imply a relationship between surface reflectance, surface texture, and flow velocity that might enable river hydraulics to be inferred from hyperspectral images, in addition to morphology. Figure 12. (A) Hyperspectral image of Rusty Bend. (B) A
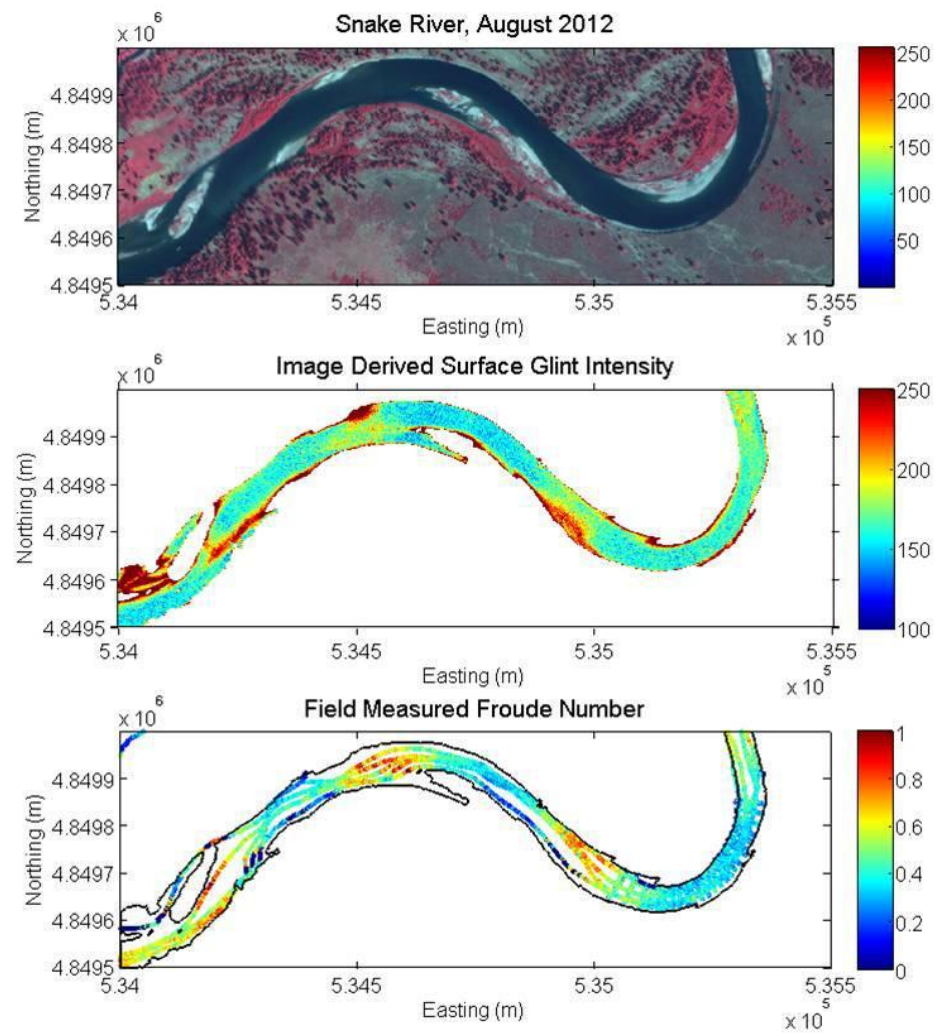

map depicting the glint intensity, or strength of the reflectance from the water surface, derived from the original hyperspectral image based on an absorption feature associated with oxygen in the atmosphere. (C) Field measurements of flow depth and velocity were used to calculate the Froude number, with areas of faster and/or shallower flow having higher Froude numbers. The similar spatial patterns in (B) and (C) imply a connection between surface reflectance, surface texture, and flow hydraulics.

Further work will be required to verify this connection and develop efficient algorithms for 
mapping velocities from hyperspectral images.

\section{Channel change: quantifying erosion and deposition}

In addition to our interest in developing remote sensing methods for characterizing large, dynamic river systems such as the Snake, our work also seeks to better understand the geomorphic history of this particular river and gain insight on the processes that have directed the channel's evolution over time. These two goals are highly complementary, as archives of remotely sensed data provide valuable, synoptic documentation of changes occurring along the river. The image data sets acquired in 2012 extend our annual time series from 2009 through the present, with additional image acquisition scheduled for August 2013.

Our previous annual report described riparian land cover classifications developed from successive images in this time series using a spectrally-based decision tree algorithm. This approach allowed us to identify portions of the valley floor that experienced a transition from one land cover type to another during the time period between images and infer the operative geomorphic process. For example, an area classified as floodplain during time 1 but active channel during time 2 would have experienced erosion, whereas a transition from active channel to gravel bar would imply deposition. These land cover transitions thus provide information on the areal extent of erosion and deposition, but calculating the volume of material involved requires additional information on the depth of scour or the thickness of sediment deposited. Repeat coverage of LiDAR topographic data are well-suited to this purpose and we obtained an existing 2007 LiDAR data set for the Snake River corridor to complement the new NCALM data acquired in 2012.

Ultimately, we intend to scale up this analysis to encompass the Snake River throughout Grand Teton National Park, but initially our efforts have focused on Swallow Bend. This reach is peculiar in that a large bar is located on the outside of the bend, whereas curved channels typically feature a point bar on the inner bank. The unusual morphology of Swallow Bend is shown in the 2012 image on the right side of Figure 13, but an aerial photograph from 1994 shows that the bar on the outside of the bend is relatively recent. Although we have several hypotheses as to what might have led to the deposition of this bar, with an 18-year gap between images identifying when this pronounced morphologic change occurred is not possible; this is why the annual time series we have now begun to accumulate is so valuable.

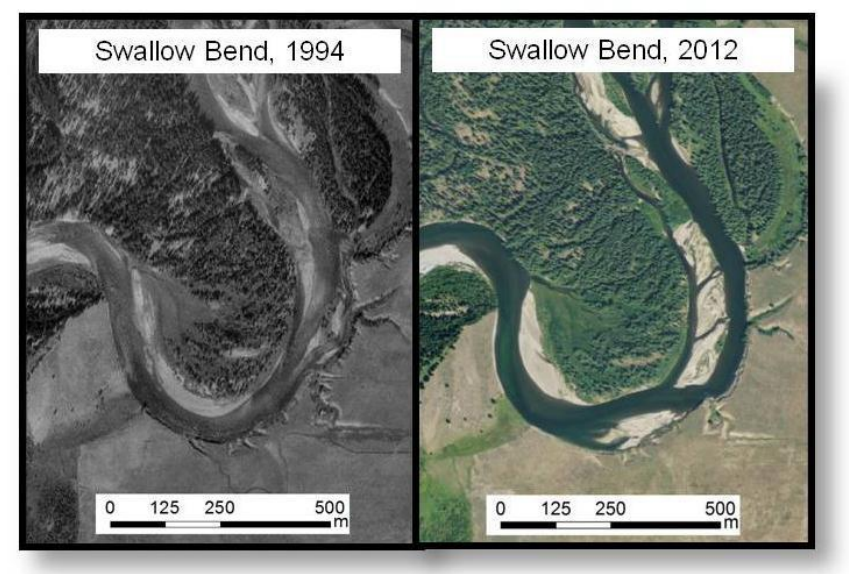

Figure 13. Historical and recent images of Swallow Bend, with the 2012 scene highlighting the large bar deposited along the outer bank.

Similarly, repeat LiDAR coverage, with 2007 and 2012 data sets already available and a new acquisition planned for 2013, allows sediment volumes to be quantified as well. By comparing sequential topographic data sets, a digital elevation model (DEM) of difference (DoD) can be produced and used to determine the depth of scour or thickness of fill. Multiplying these depths by the cell size of the DEM yields a volume. For Swallow Bend, a comparison of the 2007 and 2012 LiDAR data sets indicates that the terrace protruding into the channel along the outer bank near the entrance to the bend has retreated by several meters, with over $10 \mathrm{~m}$ of vertical erosion occurring during this time period in some locations. Movement of this eroded material downstream could lead to sediment accumulation on the bar along the outer bank, with the protruding terrace acting to deflect the flow toward the inside of the bend and allowing deposition in the zone of weaker flow below the constriction. Our future work will focus on incorporating this type of quantitative information into a sediment budgeting framework that explicitly accounts for inputs from bank erosion and storage of sediment on bars. This analysis will help refine existing sediment budgets, which are based on bedload transport measurements on the Pacific Creek and Buffalo Fork tributaries and the Snake River but do not incorporate sediment fluxes associated with bank erosion or bar deposition (Erwin et al., 2011). The resulting, refined sediment budget will help advance our understanding of the processes driving the Snake River's dynamics. 
(a) 2007 LIDAR DEM

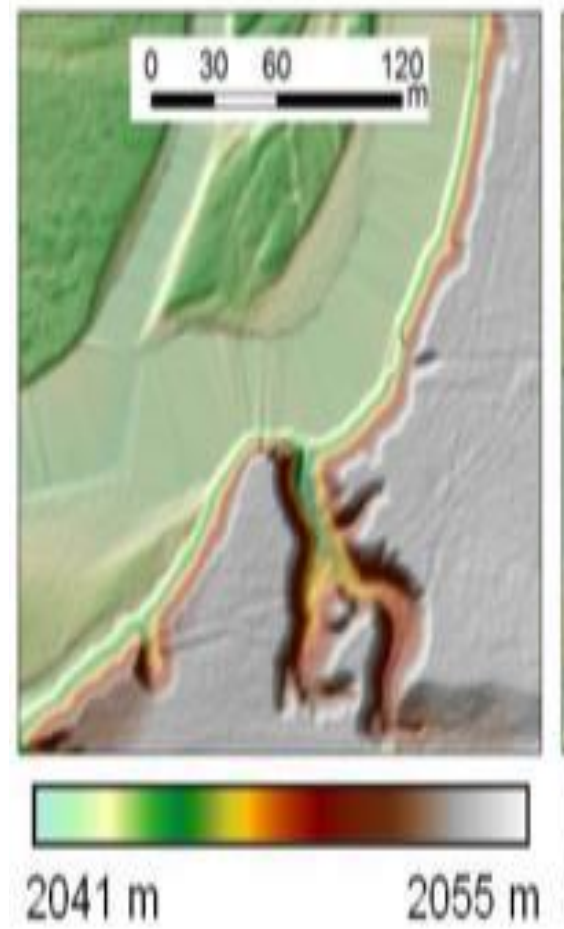

(b) 2012 LIDAR DEM

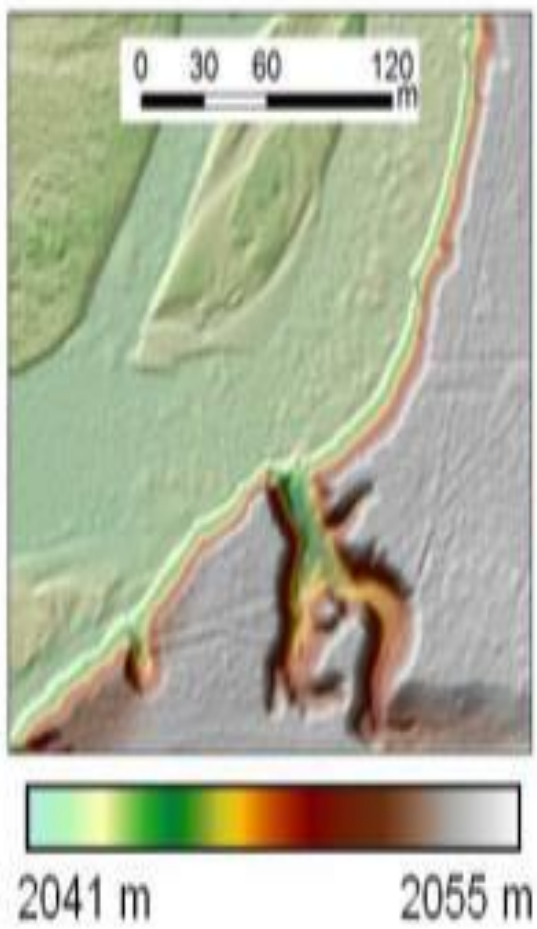

(c) DEM of change

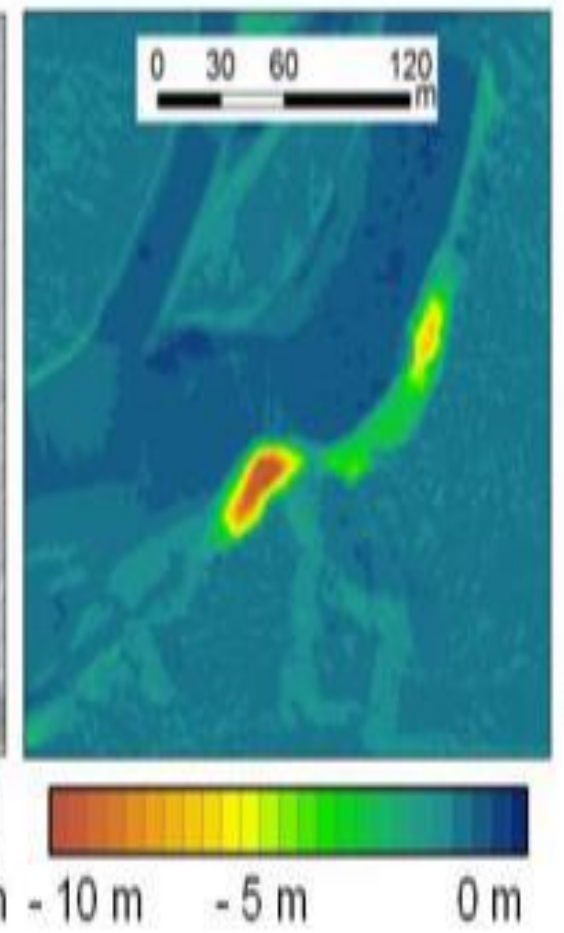

Figure 14. LiDAR topography from 2007 and 2012, with a DEM of difference highlighting erosion of the outer bank.

\section{$\uparrow$ MANAGEMENT IMPLICATIONS}

could provide a powerful tool for assessment and monitoring of riverine resources throughout the region. The 2009 Craig Thomas Snake River Headwaters Act designated the river above Jackson Lake as a Wild River and the segment from Jackson Lake Dam to Moose, along with the Pacific Creek and Buffalo Fork tributaries, as Scenic Rivers in recognition of their ecological, aesthetic, and recreational value. This legislation provides these streams with protected status as part of the National Wild and Scenic Rivers System and ensures the freeflowing condition of these waterways. Along with this designation comes the task of determining how best to preserve this remarkable fluvial system.

Accordingly, the Park Service has set out to develop a new river management plan, which will involve documenting these unique natural resources and identifying effective strategies for their protection. Park managers are thus obligated to characterize the form and behavior of the Snake River, along with the associated habitat conditions and recreational opportunities. Our primary objective is to derive such information from remotely sensed data; this continuing project will thus directly inform the Park's
This ongoing study directly contributes to the Park Service's current management priorities and river management plan. Moreover, the techniques developed as part of this investigation could be applied to other streams throughout the Snake River headwaters, both those that have already been awarded Wild and Scenic status and others that might merit such consideration in the future. Although remote sensing clearly offers significant potential to facilitate a number of river-related applications, this potential has not been realized in practice, and the capabilities and limitations of a remote sensing-based approach must first be established. By demonstrating the utility of these methods, and also acknowledging their deficiencies, this study of the Snake River could lead to more widespread, effective use of remote sensing in river research and management.

\section{$\uparrow$ ACKNOWLEDGEMENTS}

In addition to logistical support from the UW-NPS Research Station, this project received funding from the Office of Naval Research. Field work along the Snake River would not have been possible without the able assistance of Clem Rawlins. Annie Toth also contributed to the field effort. Remotely 
sensed data were acquired through collaboration with the National Center for Airborne Laser Mapping, with Juan Fernandez-Diaz and Michael Sartori leading the project. We are grateful to Kathy Mellander, Susan O’Ney, Sue Consola-Murphy, and Linda Franklin of the National Park Service for their support of our study.

\section{$\downarrow$ Literature Cited}

Erwin SO, Schmidt JC, Nelson NC. 2011. Downstream effects of impounding a natural lake: the Snake River downstream from Jackson Lake Dam, Wyoming, USA. Earth Surface Processes and Landforms, 36(11): 1421-1434.

Legleiter CJ. In press. Mapping river depth from publicly available aerial images. River Research and Applications, doi: 10.1002/rra.2560.

Legleiter CJ. 2012. Remote measurement of river morphology via fusion of LiDAR topography and spectrally based bathymetry. Earth Surface Processes and Landforms, 37(5): 499-518.

Legleiter CJ, Roberts DA, Marcus WA, Fonstad M. 2004. Passive optical remote sensing of river channel morphology and in-stream habitat: Physical basis and feasibility. Remote Sensing of Environment, 93:493-510.

Legleiter CJ, Roberts DA, Lawrence RL. 2009. Spectrally based remote sensing of river bathymetry. Earth Surface Processes and Landforms, 34:1039-1059.

Legleiter CJ, Harrison LR, Dunne T. 2011. Effect of point bar development on the local force balance governing flow in a simple, meandering gravel bed river. Journal of Geophysical Research, 116(F01005): doi: 10.1029/2010jf001838.
Legleiter CJ, Overstreet BT. 2012. Mapping gravel bed river bathymetry from space. Journal of Geophysical Research - Earth Surface, 117(F04024): doi: 10.1029/2012jf002539.

Legleiter CJ, Overstreet BT. In press. Retrieving river attributes from remotely sensed data: an experimental evaluation based on field spectroscopy at the Outdoor Stream Lab. River Research and Applications, doi:10.1002/rra.2674.

Marcus WA, Fonstad MA. 2010. Remote sensing of rivers: the emergence of a subdiscipline in the river sciences. Earth Surface Processes and Landforms, 35:1867-1872.

Mishra DR, Narumalani S, Rundquist D, Lawson M. 2005. Characterizing the vertical diffuse attenuation coefficient for downwelling irradiance in coastal waters: Implications for water penetration by high resolution satellite data. ISPRS Journal of Photogrammetry and Remote Sensing, 60(1): 48-64.

Nelson NC, Erwin SO, Schmidt JC. In press. Spatial and temporal patterns in channel change on the Snake River downstream from Jackson Lake dam, Wyoming. Geomorphology, doi:10.1016/j.geomorph.2013.03.019.

Warrick JA. et al. 2009. Cobble cam: grain-size measurements of sand to boulder from digital photographs and autocorrelation analyses. Earth Surface Processes and Landforms, 34(13): 1811-1821. 